ScIDice

\section{International Journal of Dentistry and Oral Science (IJDOS) \\ ISSN: 2377-8075}

\title{
Evaluation Of Suturing In Closed Extraction
}

Research Article

Reshmi. B ${ }^{1}$, Balakrishna $\mathrm{RN}^{2 *}$, Arvind $\mathrm{S}^{3}$

${ }^{1}$ Saveetha Dental College and Hospitals, Saveetha Institute of Medical and Technical Sciences, Saveetha University, Chennai, India.

${ }^{2}$ Senior Lecturer, Department of Oral and Maxillofacial Surgery, Saveetha Dental College and Hospitals, Saveetha Institute of Medical and Technical Sciences, Saveetha University, Chennai, 600077, India.

${ }^{3}$ Reader, Department of Orthodontics, Saveetha Dental College and Hospitals, Saveetha Institute of Medical and Technical Sciences, Saveetha University, Chennai, 600077, India.

\section{Abstract}

Extraction is the removal of teeth from its socket by elevating flaps. The extraction socket heals in a period of a week or two . They heal by secondary intention that is formation of new tissue from the base to the above. In case if its traumatic extraction healing by primary intention is a must that is suturing the edges. This will lead to faster healing of the wound and reduce postoperative complications.The aim of the study is to assess the importance of suturing in closed extraction and how many extractions are sutured .50 patients attending the OP of saveetha dental College were randomly selected. Data like age ,gender ,extraction tooth number, suturing done or not were collected. Informed consent where obtained from patients . The collector details were put in the excel sheet and segregated according to age. Then the data were transferred to SPSS software for further graphical and statistical analysis. $32.0 \%$ of the population belonging to $60-70$ didn't have suture after extraction and $13.56 \%$ had suture after extraction ( $\mathrm{P}=0.999>\mathrm{P}=0.05$, statistically not significant). This study concludes that suturing must be done more to avoid and postoperative complications.

Keywords: Closed Extraction; Complications; Healing; Suturing.

\section{Introduction}

Close extraction is also known as simple or intra alveolar take me. Suturing is any strand of material which is used to like get blood vessels or approximate tissues [Silversteen L.H 1999 ] [1]. The main aim of suturing is to maintain Haemostasis, permit primary intention [2]. Primary and secondary closure for wound healing after management of extraction [3]. In the mouth, sutures can assist the healing of gums and other soft issues by holding them in desired places [4]. In complex dental extraction such as wisdom teeth the gums must be ensured to heal in order to prevent food traps [5].

Sutures are used to approximate natural soft tissue contours [6]. Additionally, stitches used to help in the formation of healthy blood vessels and to keep grafts and membranes in place during critical healing periods [7]. For simple dental extractions suture it is not always required [8]. When there is minimal manipulation of gums and bones and the patient has a healthy immune system it is reasonable to expect that the site will heal soon [9]. It's often, Hard to tell if a patient needs a suture until the procedure is finished [10]. Sometimes even the simplest seem to track where more money is patient and work then they initially let on [11].

The magnitude of the sequelae depends on the extent of inflammatory response resulting from the extent of tissue damage produced [12] which in turn depends on certain demographics including age, gender, oral health status, and anatomic and operative factors such as increased surgical difficulty, magnitude of ostectomy, and duration of surgery [13]. Different closure techniques with or without incorporation of drains use of drugs such as analgesics corticosteroids, and antibiotics [14] and physical therapeutic methods such as cryotherapy soft laser application [15], and sutureless techniques are among the number of modalities reported in the literature to minimize postoperative pain, swelling, and trismus [16].

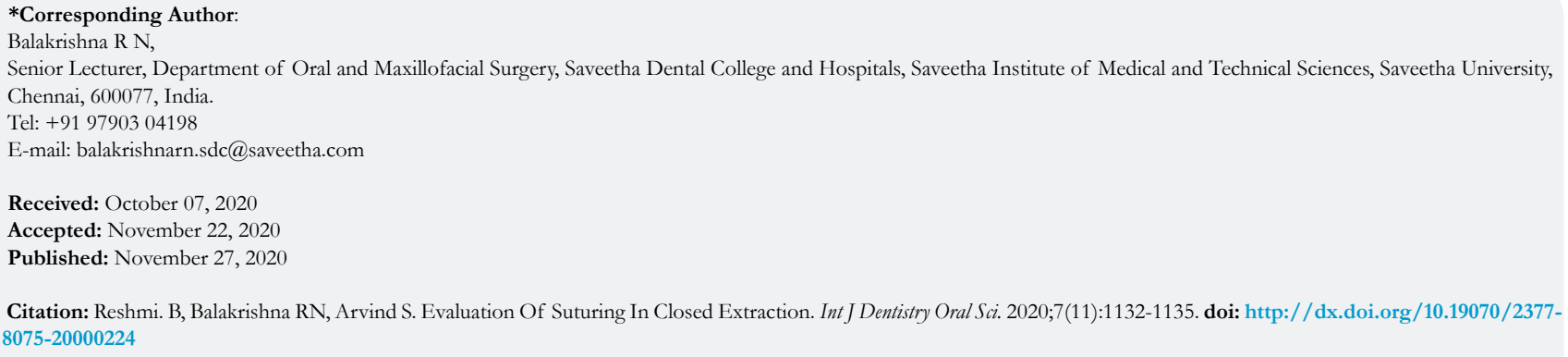

Copyright: Balakrishna RN ${ }^{\circ}$ 2020. This is an open-access article distributed under the terms of the Creative Commons Attribution License, which permits unrestricted use, distribution and reproduction in any medium, provided the original author and source are credited. 
Among the local factors that influence healing after tooth extraction, sutures play an important role. Suturing the gingiva facilitates epithelial regeneration and protects the blood clot in the initial stage of the healing process [17]. On the other hand, the suture materials employee may delay the onset of cell proliferation. Thus sutures should not be irritating to the tissues, determining short and mild inflammatory phases of healing $[18,19]$.

This study was conducted in Chennai-based college to know how many patients after extraction had suturing and quality of healing.

\section{Materials And Methods}

It is a retrospective study for which the data were collected From patients who visited Saveetha dental College OP for treatment for a period of six months.

Informed consent was obtained from the patients before the start of the study and was clearly explained to them. Ethical approval was obtained from the scientific review board of Saveetha University.

\section{Sampling}

The number of patients involved in the study were 59 patients attending the OP. The data collected were, Age, gender, tooth to be extracted and suturing done for the extracted tooth or not. The independent variable was age, gender, occupation and the dependent variable was suturing extracted socket and extraction These were collected from the dental information archiving software of the respective college. These data were added in excel sheets and segregated according to their age and gender.

\section{Statistical Analysis}

For analysis and graphical representation SPSS software was used. The data in the excel sheet was transferred to SPSS software correlation between age gender and Tooth number and Chi square between age and extracted tooth, Chi square between age and suturing were done. It is also tabulated and explained clearly through bars and pie charts.

\section{Results And Discussion}

This study consisted of male and female subjects of $42.3 \%$ female and $57.6 \%$ males [Graph 1]. Based on age 18.6\% belonged to the 20 to 30 years group, $10.1 \%$ belonged to 30 to 40 years, $20.3 \%$ belonged to 40 to 50 years, $5.1 \%$ belonged to 50 to 60 years and $45.7 \%$ belonged to 60 to 70 years[ Graph 2]. Based on gender and suturing of the extraction socket $35.5 \%$ of females had no suture and $6.7 \%$ have had suture after extraction. 35.5\% of the males did not have suture and $22.0 \%$ had suture and the $\mathrm{p}$ value was 0.062 (Graph 3) . Based on age and suturing , 5.1\% of patients of age 20 to 30 years had suture, $3.4 \%$ of age group 20 to 40 had suture, $5.1 \%$ of 40 to 50 years had suture, $1.7 \%$ of 50 to 60 years had to future and , $13.6 \%$ of 60 to 70 year had suturing after extraction. The p value was 0.995 (Graph 4).

Based on the tooth involved and suturing $5.08 \%$ of the patients had suture in the first quadrant, $8.47 \%$ of patients had suturing in both second and and third quadrants, $6.78 \%$ of the patients had suturing after extraction in fourth quadrant and the $\mathrm{p}$ value was 0.672 (Graph 5). 11.7\% females had suture in the first quadrant and $5.8 \%$ of females had suture in both second and third quadrants. $5.8 \%$ of males had suture in the first quadrant and $23.5 \%$ in second, third and fourth quadrants (Graph 6). 4.7\% females did not have suture after extraction in the both first and second quad-

Figure 1. Pie chart represents the gender wise distribution of study population ,(dark blue)males and (pink) females. This graph shows that $42.3 \%$ of the study population were females and $57.6 \%$ of them were males.

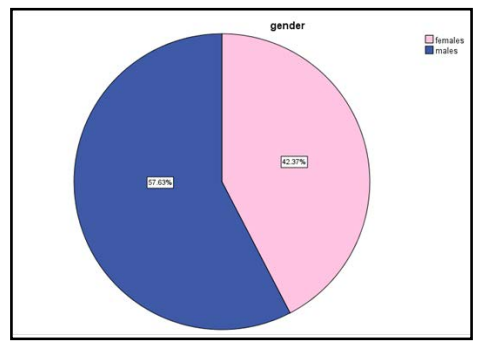

Figure 2. Pie chart represents the age wise distribution of study population . It also shows that $18.6 \%$ of the population belonged to the age group 20-30 years (maroon) , 10.1\% of the population belonged to the age group 30-40 years (grey) , 20.3\% of the population belonged to the age group 40-50 years (green) ,5.08\% of the population belonged to the age group 50-60 years(orange) and $45 . \%$ of the population belonged to the age group $60-70$ years (brown). From this we can infer that the age group of 60-70 years was high in population in this study.

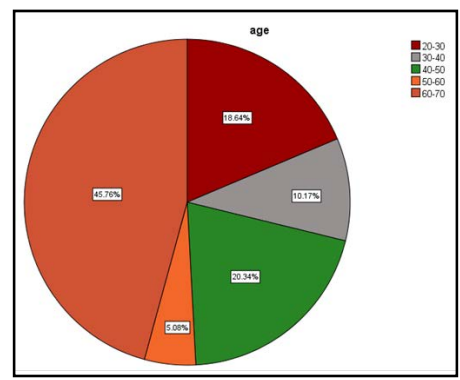


Figure 3. The clustered bar represents the distribution of study population based on age and suturing, $\mathrm{X}$ axis represents the age of the population and $\mathrm{Y}$ axis represents the percentage of study population. $32.0 \%$ of the patients belonging to the age group of $60-70$ years did not have suture followed by $13.5 \%$ patients having suture belonging to the same age group.From this we can infer that , patients did not have suture for most of extractions. $($ Chi square $=$ $0.196 ; \mathrm{Df}=4 ; \mathrm{P}=0.999>\mathrm{P}=0.05$, statistically not significant)Association of suturing based on age was statistically not significant.

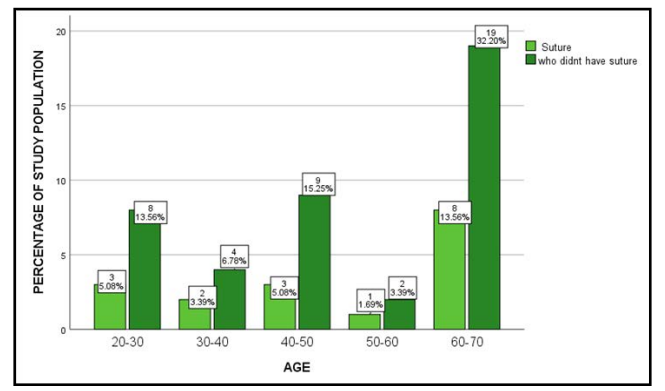

Figure 4. The clustered bar represents the distribution of study population based on gender and suturing, $\mathrm{X}$ axis represents the gender of the population and Y Axis represents the percentage of study population. $35.9 \%$ of males and females did not have suture after extraction followed by $22.3 \%$ males had suture after extraction.From this we can infer that both the genders did not have suture for most of the extraction $\cdot(\mathrm{Chi}$ square $=0.243 ; \mathrm{Df}=4 ; \mathrm{P}=0.064<$ $\mathbf{P}=\mathbf{0 . 0 5}$, statistically significant) Association of suturing based on gender was statistically significant.

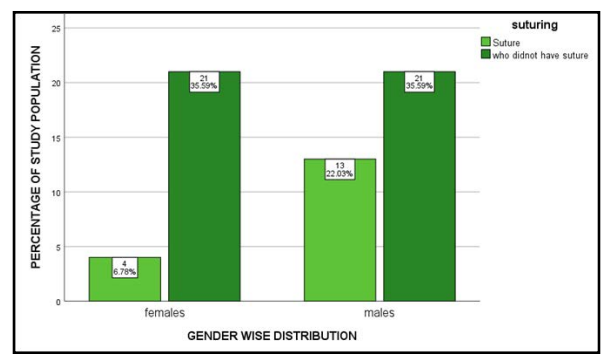

Figure 5. The clustered shows the representation of suturing and tooth extracted according to quadrant wise . $X$ axis represents the quadrant distribution and $\mathrm{Y}$ axis represents the percentage of study population. $27.12 \%$ of the patients who had extraction in the third quadrant did not have suture followed by $8.4 \%$ patients had suture in both second and third quadrants. From this we can infer that patients did not have suture for most extractions in any quadrant. ( Chi square $=0.544 ; \mathrm{Df}=3 ; \mathrm{P}=0.672>\mathrm{P}=0.05$, statistically not significant). Association of suturing based on quadrant was statistically not significant.

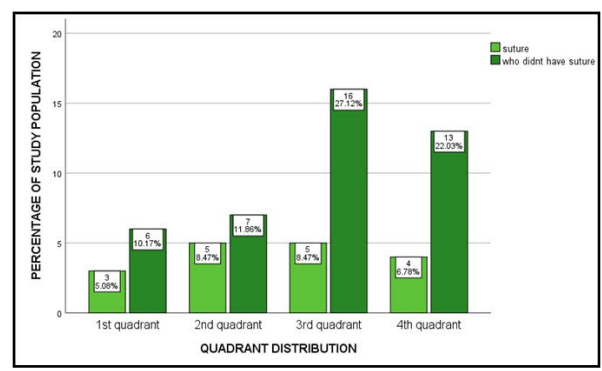

Figure 6. A multiple bar chart represents the patients who had suture after extraction based on gender. $\mathrm{X}$ axis represents the quadrant wise distribution of the study population and the $\mathrm{Y}$ axis represents the percentage of study population. From this we can infer that suture was done for males when compared to females. ( Chi square $=0.450 ; ; P=0.070>P=0.05$, statistically not significant). Association of patients who had suture based on gender was statistically not significant.

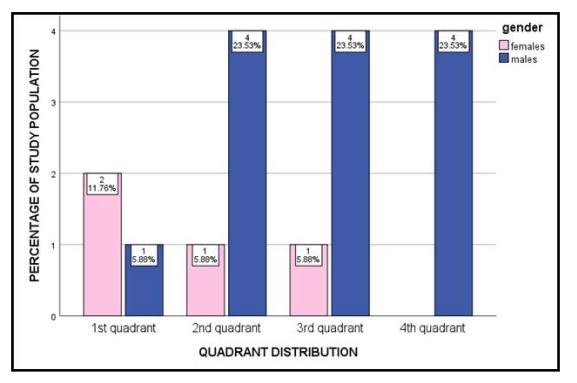

rants and $23.8 \%$ in the third quadrant and $16.7 \%$ in the fourth quadrant $.9 .52 \%$ males didn't get suture in the first quadrant and $11.9 \%$ in the second quadrant and $14.29 \%$ in the third and fourth quadrants (Graph 7).

In our study a total of $28.8 \%$ of the patient had suture and $71.2 \%$ had no suturing after extraction. In a study by cosme Gay Escoda, $47.2 \%$ had suture and $52.5 \%$ had no sutures 2 . In our study $23.5 \%$ of females had suture and $76.5 \%$ of males had suture after extraction, in a study by Kiran khande et .al $25.4 \%$ of females had suture while $74.4 \%$ males had suture [20]. In this study $8.5 \%$ of su- turing was done in the second and third quadrant while in a study by Burch . ozkan 10.8\% of suturing was done in the second and third quadrant [21]. The most important determining factor for healing is following the doctor's postoperative [22] instructions. For better healing it's not necessary that all extractions require suturing but suturing will ultimately and in healing of better quality.

The limitation of study is, limited study population and only confined to a certain geography which shall not give the required data. The future studies must include a wide variety of population and parameters for better understanding of the study. 
Figure 7. A clustered bar chart represents the patients who did not have suture after extraction based on gender. $X$ axis represents the quadrant wise distribution of the study population and the $\mathrm{Y}$ axis represents the percentage of study population. From this we can infer that suture was done for males when compared to females. ( Chi square $=0.188 ; \mathrm{P}=0.233>$ $\mathbf{P}=\mathbf{0 . 0 5}$, statistically not significant).Association of patients who did not have suture based on gender was statistically not significant.

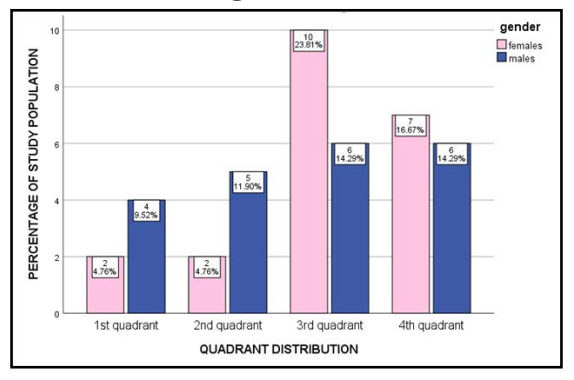

\section{Conclusion}

The conclusion of the study revealed only a few out of a simple extraction had suture. More atraumatic extractions were sutured than the traumatic extraction. For traumatic extractions suturing the sockets is a must because there is more damage to the soft tissue and delays healing and increased patients discomfort.

\section{Acknowledgment}

The authors are thankful to the Director of Saveetha Dental College and Hospital, Chennai.

\section{References}

[1]. Kudur MH, Pai SB, Sripathi H, Prabhu S. Sutures and suturing techniques in skin closure. Indian J Dermatol Venereol Leprol. 2009 JulAug;75(4):425-34. PMID: 19584482.

[2]. Gay-Escoda C, Gómez-Santos L, Sánchez-Torres A, Herráez-Vilas JM. Effect of the suture technique on postoperative pain, swelling and trismus after removal of lower third molars: A randomized clinical trial. Med Oral Patol Oral Cir Bucal. 2015 May 1;20(3):e372-7. PMID: 25662551.

[3]. Christabel A, Anantanarayanan P, Subash P, Soh CL, Ramanathan M, Muthusekhar MR, et al. Comparison of pterygomaxillary dysjunction with tuberosity separation in isolated Le Fort I osteotomies: a prospective, multi-centre, triple-blind, randomized controlled trial. Int J Oral Maxillofac Surg. 2016 Feb;45(2):180-5. PMID: 26338075.

[4]. Patil SB, Durairaj D, Suresh Kumar G, Karthikeyan D, Pradeep D. Comparison of Extended Nasolabial Flap Versus Buccal Fat Pad Graft in the Surgical Management of Oral Submucous Fibrosis: A Prospective Pilot Study. J Maxillofac Oral Surg. 2017 Sep;16(3):312-321. PMID: 28717289.

[5]. Kumar S, Snena S. Knowledge and awareness regarding antibiotic prophylaxis for infective endocarditis among undergraduate dental students. Asian J Pharm Clin Res. 2016;9:154-9.

[6]. Abhinav RP, Selvarasu K, Maheswari GU, Taltia AA. The Patterns and Etiology of Maxillofacial Trauma in South India. Ann Maxillofac Surg. 2019 Jan-Jun;9(1):114-117. PMID: 31293938.

[7]. Song PC, Schwartz J, Blitzer A. The emerging role of botulinum toxin in the treatment of temporomandibular disorders. Oral Dis. 2007 May;13(3):25360. PMID: 17448205.

[8]. Jesudasan JS, Wahab PU, Sekhar MR. Effectiveness of $0.2 \%$ chlorhexidine gel and a eugenol-based paste on postoperative alveolar osteitis in patients having third molars extracted: a randomised controlled clinical trial. $\mathrm{Br} \mathrm{J}$ Oral Maxillofac Surg. 2015 Nov;53(9):826-30. PMID: 26188932.

[9]. Kumar S, Rahman RE. Knowledge, awareness, and practices regarding biomedical waste management among undergraduate dental students. Asian
Journal of Pharmaceutical and Clinical Research. 2017;10:341

[10]. Packiri S, Gurunathan D, Selvarasu K. Management of Paediatric Oral Ranula: A Systematic Review. J Clin Diagn Res. 2017 Sep;11(9):ZE06-ZE09. PMID: 29207849.

[11]. Rahman R, Mp Sk. Knowledge, Attitude, And Awareness Of Dental Undergraduate Students Regarding Human Immunodeficiency Virus/Acquired Immunodeficiency Syndrome Patients. Asian J Pharm Clin Res. 2017;10(5):175-80.

[12]. Sweta VR, Abhinav RP, Ramesh A. Role of Virtual Reality in Pain Perception of Patients Following the Administration of Local Anesthesia. Ann Maxillofac Surg. 2019 Jan-Jun;9(1):110-113. PMID: 31293937.

[13]. Patturaja K, Pradeep D. Awareness of Basic Dental Procedure among General Population. Research Journal of Pharmacy and Technology. 2016;9(9):134951.

[14]. Vijayalakshmi B, Kumar MS. Knowledge of students about Local anaesthetics used during oral surgical procedures. Journal of Pharmaceutical Sciences and Research. 2015 Dec 1;7(12):1105.

[15]. Marimuthu M, Andiappan M, Wahab A, Muthusekhar MR, Balakrishnan A, Shanmugam S. Canonical Wnt pathway gene expression and their clinical correlation in oral squamous cell carcinoma. Indian J Dent Res. 2018 MayJun;29(3):291-297. PMID: 29900911.

[16]. Kumar S. Relationship between dental anxiety and pain experience during dental extractions. Asian J Pharm Clin Res. 2017;10(3):458-61.

[17]. Rao TD, Kumar MP. Analgesic Efficacy of Paracetamol Vs Ketorolac after Dental Extractions. Research Journal of Pharmacy and Technology. 2018;11(8):3375-9.

[18]. Okamoto T, Rosini KS, Miyahara GI, Gabrielli MF. Healing process of the gingival mucosa and dental alveolus following tooth extraction and suture with polyglycolic acid and polyglactin 910 threads. Comparative histomorphologic study in rats. Braz Dent J. 1994;5(1):35-43. PMID: 7833640.

[19]. Vijayakumar Jain S, Muthusekhar MR, Baig MF, Senthilnathan P, Loganathan S, Abdul Wahab PU, et al. Evaluation of Three-Dimensional Changes in Pharyngeal Airway Following Isolated Lefort One Osteotomy for the Correction of Vertical Maxillary Excess: A Prospective Study. J Maxillofac Oral Surg. 2019 Mar; 18(1):139-146. PMID: 30728705.

[20]. Khande K, Saluja H, Mahindra U. Primary and secondary closure of the surgical wound after removal of impacted mandibular third molars. J Maxillofac Oral Surg. 2011 Jun;10(2):112-7. PMID: 22654360.

[21]. Cetinkaya BO, Sumer M, Tutkun F, Sandikci EO, Misir F. Influence of different suturing techniques on periodontal health of the adjacent second molars after extraction of impacted mandibular third molars. Oral Surg Oral Med Oral Pathol Oral Radiol Endod. 2009 Aug;108(2):156-61. PMID: 9615653.

[22]. Ahamed A, Kumar MS. Knowledge, attitude and perceived confidence in handling medical emergencies among dental students. Journal of Pharmaceutical Sciences and Research. 2016 Jul 1;8(7):645. 